\title{
Patterns and Factors of Farming Innovation in Taiwan
}

\author{
Wan-Tran Huang ${ }^{1} \&$ Chun-Yu Chien ${ }^{1}$ \\ ${ }^{1}$ Department of Business Administration, Asia University, 500 Lioufeng Rd, Taichung 41354, Taiwan \\ Correspondence: Chun-Yu Chien, Department of Business Administration, Asia University, 500 Lioufeng Rd, \\ Taichung 41354, Taiwan. Tel: 886-958-569-779. E-mail: chien_ivy@hotmail.com
}

Received: April 19, 2013 Accepted: May 23, 2013 Online Published: June 15, 2013

doi:10.5539/jas.v5n7p269 URL: http://dx.doi.org/10.5539/jas.v5n7p269

\begin{abstract}
Agriculture is no longer considered merely as farming in this era of globalized commerce and information. The successful cases of innovative farming in Taiwan resulted from full authorization coming from their farm management, combination of marketing innovation with production technology, and consideration of cultural originality and innovation in their operations.
\end{abstract}

Keywords: farming innovation, agriculture, analytic hierarchy process (AHP)

\section{Introduction}

Agriculture is no longer considered merely as farming in this era of globalized commerce and information. The perceived negative effect of farm conventionalization is the lack of environmental and social sustainability, but the positive effect is economic sustainability (Goldberger, 2011). The regulatory requisite of freedom is best attained by downsizing democracy (Bell \& Lowe, 2000). The domestic agricultural sector of Taiwan is confronting several challenges domestically and internationally, and is facing production and marketing problems after the country joined the World Trade Organization (WTO). Aside from the importation of agricultural products, the occurrence of natural disasters, and inertia of production, one of the major difficulties is the lack of international competitiveness of the agricultural products of Taiwan due to the high costs of land and labor. The unification and the introduction of the market economy have affected rural areas (Blacksell \& Born, 2002), while the growing construction and extensive structures have changed the lives of farmers (Sligo \& Massey, 2007). According to Schumpeter, only "innovation" can make the differences between businesses, create the blue ocean, and secure sustainable operations for enterprises. Cañada and Vazquez (2005) point out that "innovation and quality knowhow in environmental and sustainable development attributes-were the core of the analysis."

Based on the Maikebote theory, farms should focus their strategy and differentiation of their agricultural products on innovation. Innovation refers to new technology and market knowledge to provide customers with new products and services. Innovation is also a creative process, and the result of which are achieved through the development of new technology or new knowledge by organizations. Innovation is applied to networks and practices. Huang (2008) points out several types of innovation in the agricultural and business sectors. These innovations include organizational, marketing, cultural, production technology, and cultural creativity. In traditional agricultural innovations, farming teams combine local culture and resources to increase their competitiveness through their core competencies. Innovations are usually assisted by professional farming organizations, such as the Farmers Association, Council of Agriculture, or producer cooperatives. However, success does not come immediately after the innovation is initiated because adjustment requires time. The first agricultural innovation in Taiwan utilized traditional biotechnology and mechanization. The secondary innovation focused on seeking individual core competencies and forming an innovative management team to ensure overall competitiveness in farming management.

This paper selects a number of farming teams with innovation experiences, and generalizes the required structure, situation, strategy, and means of overcoming challenges to create a blueprint for innovation. The objective of this paper is derived from the research perspective and the existence of several theory-related studies (Yang, 2003). However, most of the research, such as that by Huang (2005), is concerned with the factors of general management instead of innovation in farming management, which is the niche this paper focuses on. 
This paper has three major objectives, which are as follows:

1) To group different samples into four major innovation styles

2) To analyze the originality process and the success factors

3) To construct innovation models for future strategic use.

The research process included, first, the collection of necessary information from three areas of innovation, farming organizations, and the different innovation teams. Second, interviews were conducted with four domestic farming teams. The questionnaire-based interviews focused on the major management tactics, history, and purpose of the organization. The interviews probed into the innovation process of each team, and included questions regarding motives, originality, process, problems, reactions, and solutions. Third, questionnaires were collected from 45 marketing production teams within the four successful innovation farms. Data were sorted to determine how many samples were needed from each group. The design of questionnaire asked for the basic information of history, manpower, resources invested, management innovation ability, and efficiency of evaluation. Overall, this paper groups the results from the different innovation farming teams, uses the analytic hierarchy process (AHP) to analyze the factors that influenced innovation, and forms a coherent conclusion for the future strategic use of professional innovation farming organizations.

\section{Theoretical Concept and Literature Review}

The economist Joseph Schumpeter (1928) first proposed and defined "innovation" as a unique task. Since the concept of innovation was introduced, scholars have provided definitions from different perspectives. Rogers (1995) believes that innovation resides in "a person or a recipient who has considered to be a new concept or behavior" that would lead to the creation of competitive advantage. According to Evans (1998), "innovation was ecologically adapted to the region and appeared to have good potential for economic return". Innovation is the ability to see life constantly from a different viewpoint and change the way of solving problems (Weiss, 2002). Meanwhile, product innovation is the use of low capital to improve old products or to present them as "new" through new technologies or market knowledge. Leonard-Barton (1995) and Barney (1991) see core competency as the key to building the competitive advantage of an enterprise, which includes mobilized, high-value, or scarce resources, and other elements with non-imitative, irreplaceable, and similar characteristics. Afuah (1998) defines innovation as the use of new technology and market knowledge to offer new products and services to customers.

Betz (1993) emphasizes that innovation is a concept that can be used to activate or improve products, processes, and services. The concept involves the simultaneous application of product innovation, new technology, structure, and plans for the production process.

The innovation system is structured based on the quality and the relationships between innovation and knowledge diffusion, and is "the leading factor in shaping inter-institutional and inter-business coordination relationships" (Cañada \& Vazquez, 2005). Subramanian and Nilakanta (1996) divide innovation into two types: managerial and technical. Johne (1998) identifies market, product, and management innovations as the factors that contribute to the development of enterprises. Marquish (1982) classifies innovation into three types, which are breakthrough, systematic, and incremental. Holt (1983) names four types of innovation, which are technological, administrative, social/organizational, and regular. Wolf (1994) points out four factors that are influence organizational innovation. First, the organizational characteristics of workers focused on leaders and senior decision makers earlier, but were extended to other influential individuals. Second, the impact of organizational innovation on the organizational structure is very important. Organizational structure refers to the formal allocation of roles, and the control and integration of work activities across the organizational boundaries of the management mechanism (Child, 1975). The third factor is the organizational climate and culture. Fourth, the environment, specifically, the organizational and external communication, affects the quality and quantity of the ability to innovate because the flow of organizational knowledge can bring about new ideas. The organization can benefit greatly if it can cross boundaries and connect with professionals and other contacts through formal and informal communication networks. To adopt the agricultural techology should depend on the factors of personal, social, cultural, economics, innovation chacteristics (Pannell et al., 2006), education level, capital, income, farm size, awaring and having positive attitudes on the environmental (Prokopy el al., 2008), information accessing, and to associating with the best management practices (Howley, Donoghue, \& Heanue, 2012). 


\section{Research Method and Data Sources}

\subsection{Research Design and Execution}

Based on the literature on innovation, this paper summarizes the collected samples and develops the different models of innovation farming on four aspects, namely, knowledge and skills of employees, technological systems, management, and values and regulations. Professionals involved in innovation farming were interviewed in the first phase. The results were used in the second phase to generate weight percentages between different options via the AHP, which was introduced by Saaty (1980, 1986, and 1990). The purposes of the AHP are to simplify and to systematize complicated and non-systematic issues, to address the issues from top to bottom, and to quantify the options for further evaluation.

\subsection{Analytic Method for Case Study}

Conducting a case study is a way to concentrate on a single environment and strategize contingencies for future reference (Eisenhardt, 1989). Bonoma (1985) and Yin (1994) state that the case study helps to explain the complexity of each research object, and is more suitable for situations where limited research has been done because the environment is natural and not manipulated. The research object may be one or more companies, groups, or persons, and the research process focuses on a certain topic but does not manipulate the variables. The methods of data collection, including questionnaires, field work, and so on, are useful in addressing questions such as "why" and "how," and the results of which can be used in future research. The conclusion of the case study is closely related to the ability of the researcher in collecting data.

Ye (1999) divides the case study research into five steps. These steps are deciding on the case based on its research purpose, constructing the case files, interviewing various sources to find out the background, organizational structure, processes, and products of the company being studied, collecting the necessary data and information based on the research purpose and topic, and conducting analytical evaluation.

\section{Case Analysis}

\subsection{Research Case Evaluation}

Since Taiwan joined the WTO, the Council of Agriculture, and the Executive Yen have encouraged the rice-producing regions and various production teams with marketing abilities to expand their production management scale, and to highlight brand characteristics and places of origin to stimulate market demand for the product. In 2005, the Executive Yen created a specialized marketing team to promote safe and high-quality Taiwan rice. The aim of this project was to establish a highly competitive marketing system for the product domestically and internationally.

Creating high-quality products before implementing a "high value" image is a key marketing strategy. Therefore, farmers in the rice-growing region aimed to produce high-quality rice from the bottom up, seed selection, field management, use of safe insecticides, professional harvesting, packaging, and transportation. With marketing strategy and advertising, an on-site sale center was set up as a direct channel of communication with customers. To boost sales, the top priority was to make domestic consumers understand the value of Taiwan rice. After raising the sales, the profit was shared with farmers as a reward and an encouragement for their hard work. This positive cycle is the proper way to improve substantially the market image of Taiwan rice, to ensure the lifeline of the business, and to create windows of opportunity for the products to enter the international market.

The main purpose of this paper is to describe the operations and processes followed by innovation farming teams. Therefore, the results of the samples selected are divided into two parts. The first part includes an overview of each case, history, and purpose of innovation. The second part focuses on the innovation process, the ways to overcome obstacles, and the key success factors.

\subsection{Case Overview}

The four successful cases included in this paper were recognized either by the Council of Agriculture or by agriculture-related organizations. Production marketing teams were interviewed to find out how their leaders came up with innovation decisions, how the market effect was mitigated after Taiwan's entry into the WTO, how core competencies were created in the innovation process, and how various departments (including the CEO, management staff, and marketing department) coordinated with one another in establishing the innovation model.

\subsubsection{Taimali Farmers' Association (Taitung County)}

The Taimali Farmers' Association is associated with the major products of Sunny Country of Formosa (a guild). The purpose of the innovative agricultural product is to generate more income and to promote local development. 
With assistance from the government and the Council of Agriculture, the Taimali Farmers' Association remodeled several abandoned barns into two-floor hotels with a lobby, guest area, exhibition room, and food court. Some of the old machines from the barns, such as rice mills, were kept as decors. A coffee shop in the lobby was designed by local artists such that visitors could appreciate an ancient ambience while enjoying refreshments.

Based on the concept, the Farmers' Association applied at the Council of Agriculture for "special case counseling" in 2003, and remodeled the barns, which were abandoned for 11 years, into tourist attractions. The grain mill was transformed into an information center, where visitors can access the Internet. In 2004, the Farmers' Association started selling agricultural products in the hall, and soon, these products became its most profitable source of income. Since the Farmers' Association established the Sunny Country of Formosa, its management direction has focused on using biotechnology to produce health foods and goods.

\subsubsection{Dounan Farmers' Association (Yunlin County)}

The Dounan Farmers' Association aims to assist older farmers in leasing out their farmlands to young farmers, and to manage the extensive land in a progressive manner. The CEO of Dounan Farmers' Association utilizes the Japanese concept of "bank of agriculture land." The association has been leasing farmlands since 2003. The association funds the plow agency in charge of fallow ground business, and supports the exportation of Taiwan's agricultural products such as potatoes, carrots, and burdocks. A year after the CEO began his term in 1993, he discovered that the production cycle of the Taiwanese potato was different from other agricultural products, thus giving it a good market potential. Six years ago, the landlord and tenant-peasant system was established to increase employment opportunities, and to manage the agricultural lands by using advanced technology. Currently, 15 agents are in charge of potato production. In addition, another concern of the association is addressing the problem of an aging population in the rural area.

\subsubsection{Fuli Yin-Chuan Ever Farm (Hualien County)}

In July 1998, the manager launched an experiment that involved planting organic rice in one hectare of land. The objective of the innovation was simply to help his father's farming business and to assist other farmers. As a result, the Yin-Chuan Ever Farm located in Hualien County, Fuli Township, became the first and largest organic farm in Taiwan. It has established a production traceability system of farm products, and has been selected as one of the 10 best production and marketing teams. Moreover, the Tse-Xin Organic Association has recognized the organic rice produced by the Yin-Chuan Ever Farm. To start the organic production marketing team (which required at least 10 hectares of land), the manager provided organic fertilizer and guaranteed the production for farmers who were willing to take risks, and to pursue the experiment with him. He redefined the target market and even redesigned the rice bags to make them eco-friendly. He also promoted organic rice in wholesale supermarkets by emphasizing the environmentally friendly features of the product. Thus, the Yin-Chuan Ever Farm established its brand name successfully and continued to increase its sales with Yin-Chuan Organic Rice as its major product. The marketing team used microorganism products introduced by Fwusow Industry in the production and plant protection processes, and looked into the area of growing organic paddy rice seedlings to enhance further agricultural development.

\subsubsection{Li Chuan Fishing Ground (Hualien County)}

In 1962, breeding pigs, fish, and clams in the Taitung area became a trend. However, the foot-and-mouth disease resulted in a reduced demand for pork. Inspiring the wealth of natural resources of Li Chuan, the investor focused on breeding clams. The color of the juicy clams grown in Li Chuan was light yellow, thus the product was named "golden clam." Li Chuan is the only producer of such clams in Taiwan. The investor funded the innovation process of Li Chuan Fishing Ground 60 years ago. The fishing ground benefits from its natural setting. The east side of the cultivation area is the Pacific Ocean and the moisture in the atmosphere tends to condense into rain that permeates the ground and becomes an underground flow. In 1996, the "Li Chuan Golden Clam Essence" became available in the market. In 2002, Li Chuan expanded its market further by cooperating with the Taiwan Sugar Corporation. In 2006, the clam essence received a Hazard Analysis and Critical Control Point certification, which is a guarantee of food safety. In the following year, the company established its production traceability system. Li Chuan is now focusing on the development of other products related to the golden clam. 


\subsection{Innovation and Originality Processes of Individual Cases}

\subsubsection{Taimali Farmers' Association (Taitung County)}

The originality motives of the farmers' association faced transitional pressure. The originality process is as follows:

1). Preparation phase: The CEO observed the transitional needs of the farmers' association. With the help of the marketing department, the farmers' association cooperated with a designer from Northern Taiwan, and began to develop the Japanese style remodeling blueprint for the abandoned barns.

2). Development phase: After the Sunny Country of Formosa was established, the Taimali Farmers' Association tried to market its own agricultural products in 2003. Although the sale had a rough start, consumers became aware of the especially designed products of Taimali. Today, the Sunny Country of Formosa has a stable growth and offers more than 20 products to customers.

3). Integration phase: The sales of the Sunny Country of Formosa had a substantial growth in 2005 and 2006 with the help of the Council of Agriculture and newspaper advertisements. Tourists were attracted to the designs and low prices of the products. Sales grew and more locations were added.

However, the association faced the challenges of ensuring that the major structure would be preserved during the remodeling, and insufficient funds as well. As a solution to insufficient funds, the association received additional funds from the Council of Agriculture and was granted a loan from the bank. Taimali finally had enough financial support for the innovation plan. After the board of trustees approved the innovation plan, the CEO invited two experts outside of the association to assist in the plan. No insider was used in this innovation. In the end, the CEO fully authorized the experts and did not interfere in the decision making process, which was very rare in other farmer associations.

\subsubsection{Dounan Farmers' Association (Yunlin County)}

The CEO of Dounan Farmers' Association initiated the originality motivation on innovation because the association wanted to prevent agricultural lands falling into disuse. The originality process is as follows:

1) Preparation phase: Farmers in Taiwan were to be compensated by the government during fallow. Due to the high production expense, it is difficult for lessors to rent out the fallow farmlands unless the leaser can ensure the profit will be higher than governmental compensation. To find interested leasers, the Dounan Farmers' Association provided leasers NT 10,000 higher compensation than the government has to offer as long as the farmer authorized the association to do the farming. In addition to being free of expenses, the farmers were able to choose either to authorize the planting during the first or the second session.

2) Development phase: The Dounan Farmers' Association policy encouraged farmers to lease more of their farmlands. The leased land areas have expanded to more than 140 hectares. The Dounan Farmers' Association constructed the leasing farming kingdom in southern Taiwan.

3) Integration phase: The CEO and the innovation team went to Japan to investigate the crops that had higher export potential, and the association invested in carrots, potatoes, and burdocks.

The obstacles the association faced included why farmers should lease their farmlands to the farmers' association if they could be compensated by the government during fallow. To solve this problem, the association offered higher compensation. As a result, the Dounan Farmers' Association was successful because of the innovation in production technology. The Dounan Farmers' Association built the production traceability system, which modernized the management and quality control from production to packing. In addition, monitors, PDAs, and GPS were used in the production process to control environment and crop information. The farmers' associations noticed that Taiwan's carrots and potatoes were produced in different seasons from that of other countries, and have high potential to be exported. To accommodate the Japanese market, Dounan adjusted the size of the carrots by using modern farming technology In addition, Dounan also exported burdock to Hong Kong and Japan.

\subsubsection{Fuli Yin-Chuan Ever Farm (Hualien County)}

The Fuli Yin-Chuan Ever Farm faced the obstacles of low production and low on sales volume. Hence, the manager's motivation on innovation was simply to help his father's farming business and other farmers improve their current situation. The originality process is as follows:

1) Preparation phase: Zhao-Xuan Lai started organic farming in his father's three and a half hectare land. Farming without insecticides and chemical fertilizers resulted in a drop in production level. Farmers around 
the Yin-Chuan Ever Farm did not think his organic farming strategy could last long. Lai even paid farmers to try organic farming.

2) Development phase: Due to the lack of knowledge in organic farming, he could not make enough sales for his organic rice. He had to go to the supermarket to market the product every weekend, but the result was still poor. During this phase, he sold all of the organic rice to wholesalers at a low price and almost went bankrupt.

3) Integration phase: The farmlands of Yin-Chuan Organic Rice expanded gradually. More farmers agreed to Lai's farming technique and joined the production and marketing team. Yin-Chuan Organic Rice eventually developed its brand name, and its products were exported overseas, including Hong Kong, Singapore, Canada, and Malaysia.

The manager adjusted the farming concept, redesigned the packaging, and repositioned the product in the high quality market to resolve the poor sales performance. In addition, the company advertised that organic rice protected the environment and conserved living resources. As a result, the campaign introduced the brand name and established selling channels. Yin-Chuan organic rice was also advertised in high-end department stores, such as Shinkong Misukoshi, Inageya, and Dayeh Takashimaya, through samples and product exhibitions. In addition, the manager's wife was always accessible through the 1-800 number to answer any questions and concerns from customers. The satisfaction-guaranteed service was also another effective marketing technique. The manager combined marketing techniques with local culture. Yin-Chuan Ever Farm planned to construct the bridge that would connect the city and the rural area through the management of an eco-friendly educational farm. The manager conducts a production tour for customers to help them understand the production process of organic rice better, and to maintain the brand loyalty of the customers.

\subsubsection{Li Chuan Fishing Ground (Hualien County)}

Li Chuan Fishing Ground was motivated to innovate because of the lack of funds. The founder's son observed that the current purchasing model was too risky for the breeding business. Therefore, he created his own brand name, successfully bred the golden clam, and made available "Lu Chuan Golden Clam Essence" in the market in 2006. The process of innovation is as follows:

1) Preparation phase: Li Chuan fishing ground was established 60 years ago by the founder. He improved his breeding business, which increased the size and quality of the clams. Li Chuan's golden clam became popular because of this innovation.

2) Development phase: In 2000, Li Chuan started to collaborate with Taiwan Sugar Cooperation. To ensure the quality of the golden clam, Li Chuan employed the help of professional managers to work with the National Don Hwa University's Innovation and Cultivating Center. This collaboration further improved the technology in the fishing ground. Li Chuan also opened some related classes for local fishing farmers to learn systematically from the experiences of Li Chuan.

3) Integration phase: The Innovation and Cultivating Center of Don Hwa communicated with the local farming business to initiate the farming tour, helped Li Chuan to go through the pioneer phase, and developed the Li Chuan breeding area.

The four brothers were in charge of finance, public relations, breeding, product innovation, and leisure tour business. If anyone were to bring up a new management strategy, everyone will exert effort in its implementation. Everyone was also responsible for his own idea. The results of the innovation are seen in several areas. First, in the innovation of breeding technology, new technology was used to breed the one of a kind "Golden Clam." Second, the private brand, "Lu Chuan Golden Clam Essence" combined with the experience of Li Chuan in breeding and the technology of Taiwan Sugar Cooperation successfully assisted in the marketing strategy and the increased sales in 2006. Third, combining with local culture, "the hometown of Golden Clam" drew significant amount of attention to the Li Chuan fishing ground. The current manager also used this interest to promote the new "pick clams on your own" activity to attract tourists.

\subsection{Analysis of Factors Affecting Farming}

After the data were obtained from the 4 cases and 45 production marketing teams, AHP was used to analyze the factors that led to the success of innovation farms. The analysis developed four innovation types.

\subsubsection{Organizational Innovation}

The organizational innovation type of farming teams indicated that authorization from the management department is the most important factor in organizational innovation. Other important innovation factors include 
personality of the key person, member communication, product content, channel strategy, and producing technology/product combination (Figure 1). Organizational innovation generates the best results through the leadership of the key person, the full authorization of the management department, the effective communication between members, and the different marketing strategies to promote the products.
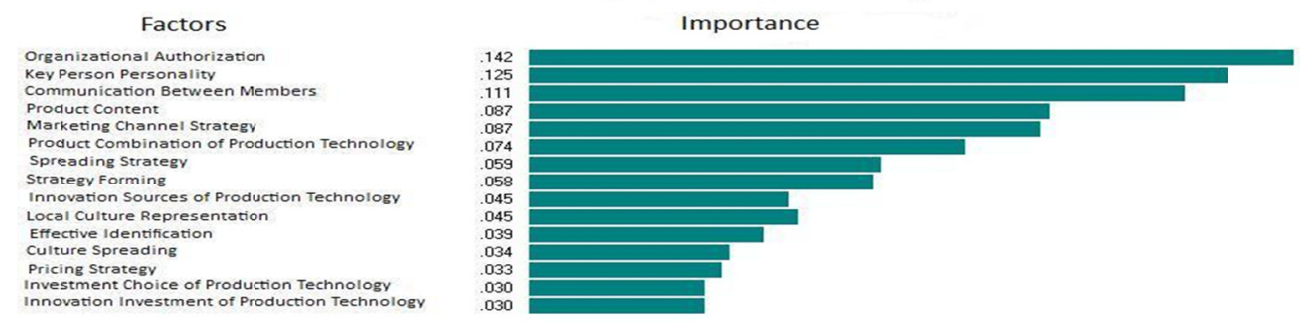

Figure 1. Factor percentage for organizational innovation

\subsubsection{Marketing Innovation}

The marketing channel strategy of farming team considered the investment choice of production technology and innovation investment of production technology as most important. The next choices are identification, communication between members, and product content. Since marketing is the focus of this approach, the construction of marketing channels needs to combine with local culture (Figure 2). In addition, this approach also requires communication between members, which would increase satisfaction within the team before marketing the products to the consumers.

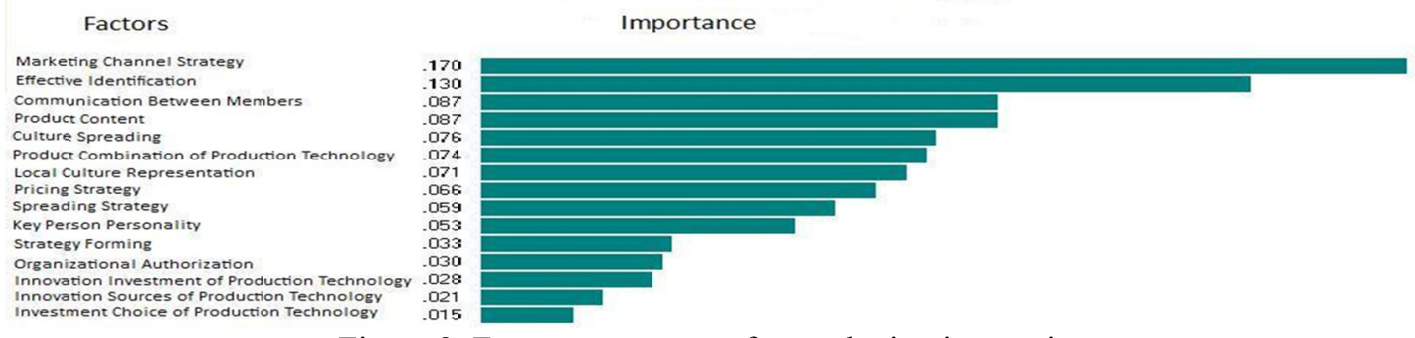

Figure 2. Factor percentages for marketing innovation

\subsubsection{Production Technology Innovation}

Business owners who utilize this approach considered the product combination of production technology as the key factor in innovation. Interviewees from the production technology innovation type of farming paid close attention to the investment cost since this type of innovation required a massive number of workers and amount of time (Figure 3). Aside from investing in technology, business owners also redesigned the combination of products to segment the market, and to bring instant profit.

\section{Factors}

Product Combination of Production Technology
Product Investment of Production Technology Product Investment of Production Technology Marketing Channel Strategy Product content

of Production Technology Effective Identifiaction

Innovation Sources of Production Technology Spreading Strategy

Culture Spreading

Strategy Formin

Pricing Strategy

Local Culture Representation

Organizational Author

Figure 3. Factor percentages for production technology innovation

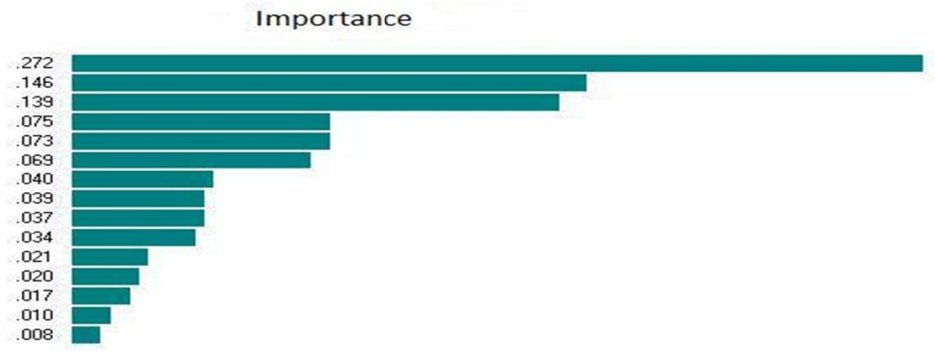




\subsubsection{Culture Originality Innovation}

Culture originality innovation teams considered local culture representation as the ultimate goal in this approach. Culture originality has to go hand-in-hand with the marketing originality execution team. The factor of marketing ability usually weighed more than culture originality ability in the questionnaire. Marketing strategy has to consider product content, and to add the culture element to popularize the product successfully (Figure 4).
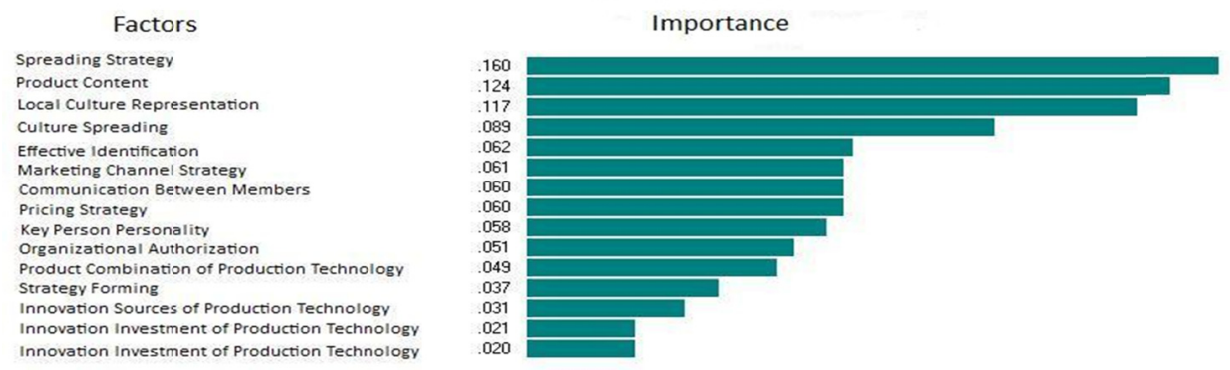

Figure 4. Factor percentages for culture originality innovation

\subsection{Assessment Results of Rice Production and Sales}

The rice production and sales in the professional district were assessed and investigated based on benefit-satisfaction. Based on the assessment, $90 \%$ of the customers were most satisfied, but $87.20 \%$ responded that the product could still be improved. Meanwhile, $85.60 \%$ opted to improve market competitiveness, and $80 \%$ responded that improvement should be continuous. For improving the whole efficiency, $81.60 \%$ were satisfied, and $64 \%$ were very satisfied (Table 1). From the assessment, the selling to a professional district, innovating, and improving a product, such as rice, can increase customer loyalty, improve market competitiveness, and satisfaction.

Table 1. A rice produces and sells the professional analytical table of district satisfaction to innovative benefit

\begin{tabular}{|c|c|c|c|c|c|c|}
\hline & Very unsatisfied & Unsatisfied & $\begin{array}{l}\text { There is } \\
\text { no suggestion }\end{array}$ & Satisfied & Very satisfied & Whole satisfaction \\
\hline Improve customer's loyalty & -- & -- & $20.00 \%$ & $10.00 \%$ & $70.00 \%$ & $90.00 \%$ \\
\hline Raise the price of the products & -- & -- & -- & $64.00 \%$ & $36.00 \%$ & $87.20 \%$ \\
\hline Improve the market competitiveness & -- & -- & $36.00 \%$ & -- & $64.00 \%$ & $85.60 \%$ \\
\hline Can prevent the products from eliminating & -- & -- & -- & $100.00 \%$ & -- & $80.00 \%$ \\
\hline Improve additional value & -- & -- & -- & $100.00 \%$ & -- & $80.00 \%$ \\
\hline Increase and apply for the subsidy & -- & $36.00 \%$ & -- & -- & $64.00 \%$ & $78.40 \%$ \\
\hline Improve the output & -- & -- & $64.00 \%$ & -- & $36.00 \%$ & $74.40 \%$ \\
\hline Buy continuously & -- & -- & $64.00 \%$ & -- & $36.00 \%$ & $74.40 \%$ \\
\hline Shorten the necessary time of production & -- & -- & $36.00 \%$ & $64.00 \%$ & -- & $72.80 \%$ \\
\hline Raise the quality & -- & -- & $36.00 \%$ & $64.00 \%$ & -- & $72.80 \%$ \\
\hline Improve the occupation rate of market & -- & -- & $64.00 \%$ & $36.00 \%$ & -- & $67.20 \%$ \\
\hline Increase staff's centripetal force & -- & -- & $100.00 \%$ & -- & -- & $60.00 \%$ \\
\hline Rate of employee turnover decreased & -- & -- & $100.00 \%$ & -- & -- & $60.00 \%$ \\
\hline Increase and sell in other areas & -- & $36.00 \%$ & $64.00 \%$ & -- & -- & $52.80 \%$ \\
\hline Reduce the production cost & -- & $44.00 \%$ & $56.00 \%$ & -- & -- & $51.20 \%$ \\
\hline Accord with the norm & -- & $72.00 \%$ & $16.00 \%$ & -- & $12.00 \%$ & $50.40 \%$ \\
\hline Improve whole efficiency & -- & $20.00 \%$ & $16.00 \%$ & -- & $64.00 \%$ & $81.60 \%$ \\
\hline
\end{tabular}

Source: this study. 


\section{Conclusion and Recommendations}

\subsection{Conclusion}

In this highly commercial and globalized information era, agriculture is no longer considered as mere farming. The essence of agriculture is based on an economic perspective. Like the management philosophy in regular enterprises, originality, innovation, and brand are also essential elements in agricultural management. According to Schumpeter, only innovation can cause the difference between businesses, create a blue ocean, and secure sustainable operations for an enterprise. Innovation is what the agriculture managers and organizations have to face at present. However, most agriculture managers and organizations do not know where to begin to improve their business.

This research was based on materials about domestic foreign capital, and studies of experts and scholars who referred to innovation in agriculture. This study incorporates the methods of diagnosing businesses and innovations for analyzing the agricultural enterprises in the cases. The analysis can determine the competitive advantages of agricultural enterprises, while understanding clearly the role of environmental analysis and management tactics.

In this research, the Taimali Farmers' Association's organizational innovation of remodeling the abandoned barns into hotels, the organic rice in Fuli Township, and Li Chuan Fishing Ground's golden clam are successful innovations. The common characteristics of all the successful cases include. authorization from the management department, use of marketing innovation as an approach, combination of production technology, and consideration of culture originality in the innovation.

Organizational type of innovation farming teams see authorization from the management department as the most important factor in organizational innovation. The content of products, marketing channel strategy, and product combination of production technology can also improve the results of innovation. Farming teams using marketing innovation approaches focus on the constructing of marketing channels. With the help of effective identification and cultural integration, local residents accepted the product. In addition, inner satisfaction between members is the required factor before sending the product to the outer market.

Business owners within the production innovation group considered product combination of production technology as the key factor in innovation. Market segmentation is made through different product combinations. With the massive investment in workers, time, technology, and effective marketing strategy, farming teams will be able to bring in instant profit. In addition, culture originality innovation teams considered marketing ability weighing more than culture originality ability in this approach. In addition, marketing strategy has to take the product content into account and add the culture element to popularize the product successfully.

\subsection{Recommendations}

The agriculture business in Taiwan faces the challenge of foreign agricultural products, and has relatively low margins compared with other businesses. The risk of failure is high for people who are not familiar with the industry. Therefore, the Council of Agriculture and farmer associations are currently working on the regeneration of the rural areas to ensure the profitability of agriculture. By doing this research, this paper suggests that the authority should begin with two areas:

Suggestion on farming management:

1) Prospectors who are interested in innovation farming should be familiar with the crops and local condition.

2) Prospectors who are interested in innovation farming should utilize production technology innovation to endow the product with the local culture, and segment the market.

3) Prospectors who are interested in innovation farming should combine innovation ability with originality.

Supplemental policy/assisting strategy for the concerned authorities:

1) Innovation farming related courses for prospectors who want to pursue further education should be available. Farming can be segmented into four categories and related to the different approaches of innovation. For example, agricultural farming goes with production technology innovation, fishing-related farming goes with organizational innovation, and the rest goes with marketing technology innovation.

2) Proprietors of the place of origin, manufacturing, storage, and retailing should be integrated to localize market segmentation. The creation of internet marketing channels could enhance the sales volume.

3) The successful innovation models should be duplicated. The national agricultural management of Taiwan 
is facing many challenges in this era. Foreign agricultural products are imported at lower costs because of the WTO membership of Taiwan, which made it even more difficult for the domestic products to compete. In addition, natural disasters, the production, and marketing traceability systems may cause other concerns in local agricultural competition.

Taiwan's agricultural management is in need of a second innovation revolution to increase its competitiveness. How to utilize and distribute limited resources effectively to increase the competitiveness in the innovation pattern are the keys to the success of the farming teams. Market segmentation affects marketing localization. With the help of the elements of the local culture (history and ecology), farming teams could successfully accomplish the innovation process and achieve their sales goals.

\section{Reference}

Afuah, A. (1998). Innovation management: strategies, implementation, and profit. New York: Oxford University Press.

Barney, J. (1991). Firm Resources and Sustained Competitive Advantage. Journal of Management, 17(1), 99-120. http://dx.doi.org/10.1177/014920639101700108

Bell, M. M., \& Lowe, P. (2000). Regulated freedoms: the market and the state, agriculture and the environment. Journal of Rural Studies, 16(3), 285-294. http://dx.doi.org/10.1016/S0743-0167(99)00062-5

Betz, F. (1993). Strategic Technology Management. NY: McGraw Hill.

Blacksell, M., \& Born, K. M. (2002). Rural property restitution in Germany's New Bundeslander: the case of Bergholz. Journal of Rural Studies, 18(3) 325-338. http://dx.doi.org/10.1016/S0743-0167(02)00009-8

Bonoma, T. V. (1985). Case research in marketing: Opportunities, problems, and a process. Journal of Marketing Research, 22(May), 199-208. http://dx.doi.org/10.2307/3151365

Cañada, J. S., \& Va'zquez, A. M. (2005). Quality certification, institutions and innovation in local agro-food systems: Protected designations of origin of olive oil in Spain. Journal of Rural Studies, 21(4), 475-486. http://dx.doi.org/10.1016/j.jrurstud.2005.10.001

Child, J. (1975). Organization structure, environment and performance: The role of strategic choice. Sociology, 6, 1-22. http://dx.doi.org/10.1177/003803857200600101

Eisenhordt, K. (1989). Building theories from case study research. Academy of Management Review, 14(4), 532-550.

Evans, P. T. (1988). Designing agroforestry innovations to increase their adoptability: a case study from Paraguay. Journal of Rural Studies, 4(1), 45-55. http://dx.doi.org/10.1016/0743-0167(88)90078-2

Goldberger, J. R. (2011). Conventionalization, civic engagement, and sustainability of organic agriculture. Journal of Rural Studies, 27(3), 288-296. http://dx.doi.org/10.1016/j.jrurstud.2011.03.002

Holt, K. (1983). Product innovation Management. London: Oxford, Butter worth Henemann, Harper Business.

Howley, P., Domoghue, C. O., \& Keanue, K. (2012). Factor affecting farmers' adoption of agricultrual innovations: A panel data analysis of the use of artificial insemination among dairy farmers in Ireland. Journal of Agricultural Science, 4(6), 171-179. http://dx.doi.org/10.5539/jas.v4n6p171

Huang, W. T. (2005). The development of the innovation farming culture in Taiwan-case of Taitung County. Technology Research Plan, Council of Agriculture, Executive Yuan.

Huang, W. T. (2008). The patterns and Development of Innovation Farming Teams in Taiwan. Tha Management Diagnosis and Guidance of Innovation Farming, Council of Agriculture, Executive Yuan, Taiwan.

Johne, A. (1998). Using mark vision to steer innovation. Technovation, 19, $203-207$. http://dx.doi.org/10.1016/S0166-4972(98)00112-6

Leonard-Barton, D. (1995). Wellsprings of Knowledge. Boston: Harvard Business School Press.

Marquish, D. G. (1982). The anatomy of successful innovation. Cambridge: Winthrop Publishers.

Pannel, D. J., Marshall, G. R., Barr, N., Curtis, A., Vanclay, F., \& Wilkinson, R. (2006). Understanding and promoting adoption of conservation practices by rural landholders. Australian Journal of Experimental Agriculture, 46, 1407-1424. http://dx.loi.org/10.1071/EA05037 
Prokopy, L. S., Floress, K., Klotthor-Weinkauf, D., \& Baumgart-Getz, A. (2008). Determinants of agricultural best management practice adoption: Evidence from the literature. Journal of Soil and Water Conservation, 63(5), 300-311. http://dx.doi.org/10.2489/jswc.63.5.300

Rogers, E. M. (1995). Diffusion of innovation (4th ed.). New York: The Free Press.

Satty, T. L. (1980). The Analytic Hierarchical Process. New York: McGraw-Hill. http://dx.doi.org/10.1287/mnsc.32.7.841

Satty, T. L. (1986). Axiomatic Foundation of the Analytic Hierarchical Process. Management Science, 32(7), 841-855. http://dx.doi.org/10.1287/mnsc.36.3.259

Satty, T. L. (1990). An exposition of the AHP in reply to the paper, remark on the Analytic Hierarchical Process. Management Science, 36(3), 259 - 280.

Schumpeter, J. (1928). The instability of capitalism. Economic Journal, 361-386. http://dx.doi.org/10.2307/2224315

Sligo, F. X., \& Massey, C. (2007). Risk, trust, and knowledge networks in farmers' learning. Journal of Rural Studies, 23(2), 170-182. http://dx.doi.org/10.1016/j.jrurstud.2006.06.001

Subrmanian, A., \& Nillakanta, S. (1996). Organization Innovativeness: Exploring the Relationship between Organizational Determinants of Innovation, Types of Innovations, and Measures of Organizational Performance, Omega International. Journal of Management Science, 24(6), 631-647.

Weiss, J. (2002). Creativity in the workplace-A much needed (and valued) asset. Women in Business, 54(4), $40-45$.

Wolfe, R. A. (1994). Organizational innovation: Review critique and suggested research directions. Journal of management studies, 31(3), 405-430. http://dx.doi.org/10.1111/j.1467-6486.1994.tb00624.x

Yang, Z. (2003). Research of innovation team creating process-take performance group as an example. National Cheng Chi University.

Yin, R. K. (1994). Case study research: Design and methods (2nd ed.). Thousand Oaks: CA: Sage Publications Ltd.

\section{Copyrights}

Copyright for this article is retained by the author(s), with first publication rights granted to the journal.

This is an open-access article distributed under the terms and conditions of the Creative Commons Attribution license (http://creativecommons.org/licenses/by/3.0/). 